\title{
Effect of curing condition on mechanical property of cold recycling mixture with foamed asphalt \\ Tian-shui Ouyang ${ }^{\mathrm{a}}$, Xiu-neng Fang ${ }^{\mathrm{b}}$, Wan-ping Wang ${ }^{\mathrm{c}}$
}

Ganzhou Management Center, Jiang Xi Provincial Expressway Investment Group Co., Ltd,

\author{
Ganzhou, 341000, China \\ a318661112@qq.com
}

Keywords: foamed asphalt; cold recycling mixture; curing condition; mechanical property

\begin{abstract}
Curing condition is one of the most important parts in the mix design of cold recycling mixture with foamed asphalt. A reasonable choice of curing condition can improve the consistency between the indoor mixture proportion design and the construction. The effects of different curing conditions on mechanical property of cold recycling mixture with foamed asphalt were studied by conducting the indirect tensile strength test (ITS) and optimum moisture content test. The influence of curing conditions on the strength of cold recycling mixture with foamed asphalt mixture was revealed. The results showed that when specimens were placed into an air-circulating oven at $60^{\circ} \mathrm{C}$ for 40h, the rates of moisture loss and strength growth in cold recycling mixture were rapidly. So, the curing age of mixture did not have to be extended after the curing for 3d. When specimens wrapped in the plastic bags with sealing were placed into an air-circulating oven at $40^{\circ} \mathrm{C}$ and curing for $48 \mathrm{~h}$, the rates of moisture loss and strength growth of recycling mixture were slowly and the hydration reaction of cement could accomplish adequately, promoting the sufficient formation of the strength. The cold recycling mixture with foamed asphalt in cement stabilized base had a greater strength and moisture content under the sealed curing condition at $40^{\circ} \mathrm{C}$. It can provide theoretical basis for guiding the construction.
\end{abstract}

\section{Introduction}

The cold recycling mixture with foamed asphalt in the cement stabilized base is a kind of multiphase material consisted of foamed asphalt, reclaimed cement stabilized base (RCTB), cement and water, which is commonly applied in a base or subbase of highway and under the stresses of tensile, compressive and shear. Different curing environment will lead to a great impact on the strength of the recycling mixture [1, 2]. At present, the research on cold recycling mixture with foamed asphalt mainly focuses on the evaluation of pavement performances of foamed asphalt and its mixture, lacking the experimental study of the formation process of strength $[3,4,5,6]$. $\mathrm{Li}$ conducted a study on the pavement performance of foamed asphalt mixture by changing the gradation, water consumption and asphalt content [7]. Jenkin had a research on the moisture stability of cold recycling mixture with foamed asphalt and comparative analyzed the effect of different dosage of reclaimed asphalt concrete on the performance of cold recycling mixture [8]. KWEIR conducted an analysis on the foaming process of foamed asphalt, and then researched the influence factors of foamed asphalt mixture, including the initial water content, water quantity change and compaction energy, etc [9]. It can be found from the above research status at home and abroad, the influence study of curing condition on cold recycling mixture with foamed asphalt was not enough in-depth $[10,11]$. At present, the determination of curing condition was mainly based on engineering experience. The uncertainty about the effect of curing condition on the performance of foamed asphalt mixture led to different practice in process of the actual project operation.

This paper is to study the effect of curing condition on the mechanical property of cold recycling mixture with foamed asphalt, and provides theoretical basis for exploring strength development rule of foam asphalt mixture change, optimizing the design of mixture proportion and studying long-term pavement performance. 


\section{Curing Condition}

2.1 Strength analysis of cold recycling mixture with foamed asphalt in the cement stabilized base

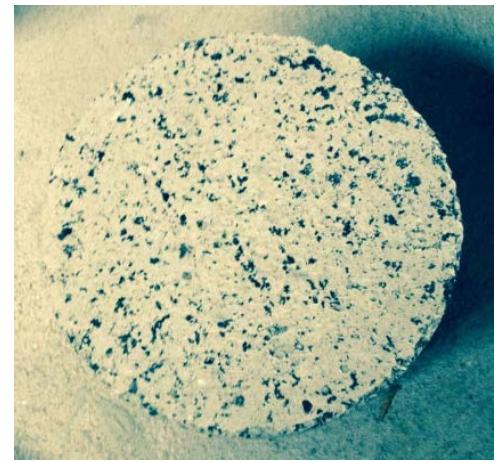

Fig. 1 Marshal sample

Before forming uniform foamed asphalt mixture, asphalt should be foamed, with the sharp increasing of volume and the reducing of viscosity. It can be seen from the Fig 1, in recycled mixture, most of foamed asphalt adhered with fine aggregates (less than $0.075 \mathrm{~mm}$ ) to form tiny particles, which evenly distributed in the cold recycling mixture, and embed in the larger aggregate, so as to generate the overall strength. It was worth noting that the millimeter-sized particle could be able to distinguish by eyes.

Table 1 showed the results of splitting test and unconfined compressive strength test for the standard Marshall specimen prepared by RCTB material. Obviously, the mechanical interaction provided by clamp lock function of aggregates and the adhesion provided by the aggregate itself, did little contribution to the tensile strength of mixture. And the tensile and compressive strength of cold recycling mixture were mainly caused by the adhesion of foamed asphalt and cement.

Table 1 Results of mechanical experiments of RCTB material

\begin{tabular}{|c|c|c|}
\hline Material type & $\begin{array}{c}\text { Dry splitting strength } \\
(\mathrm{KPa})\end{array}$ & $\begin{array}{c}\text { Unconfined compressive strength } \\
(\mathrm{MPa})\end{array}$ \\
\hline RCTB & 0.09 & 2.754 \\
\hline Recycling mixture & 0.64 & 0.566 \\
\hline Proportion & $14 \%$ & $21 \%$ \\
\hline
\end{tabular}

\subsection{Curing condition}

The different curing conditions including temperature, humidity and age could cause great influence on the strength and performance of the foamed asphalt mixture. Previous research has shown that compared with the curing temperature of $40^{\circ} \mathrm{C}$, the foamed asphalt mixture under the curing temperature of $50^{\circ} \mathrm{C}$ was easier to cause obvious rheological and high temperature dispersion [12, 13]. In the traditional non-closed curing condition, the uncontrollability of relative humidity was easy to influence the repeatability and reproducibility of relative experiments for recycling mixture. As the growth of the curing age, the strength of the mixture would increase gradually [14, 15]. Therefore, the effect study of different curing environment on the properties of cold recycling mixture with foamed asphalt is the key to improve the performance of foamed asphalt mixture.

\section{Experiment Design}

\subsection{Materials}

\subsubsection{Foamed asphalt}

This paper used small foaming device named Wirtgen WLB 10S to conduct the preparation of foamed asphalt for China Offshore 70\# asphalt, as shown in Fig 2. The result of foaming test was shown in Table 2 . The environmental temperature was $28^{\circ} \mathrm{C}$ and humidity was $83 \%$. 


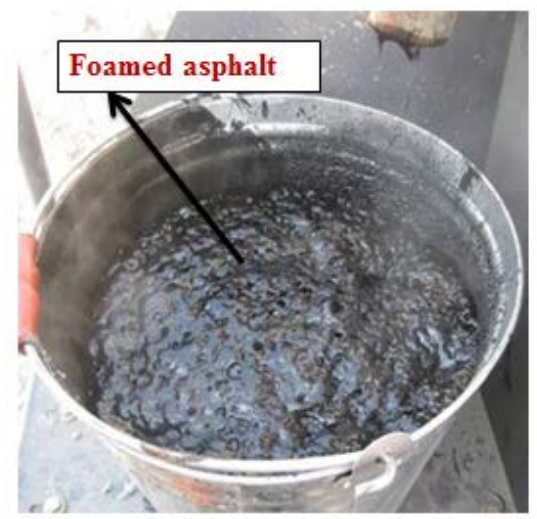

Fig. 2 Foamed asphalt

Table 2 Foaming test of China Offshore 70\# asphalt

\begin{tabular}{|c|c|c|c|c|c|c|}
\hline \multirow{3}{*}{$\begin{array}{c}\text { Water } \\
\text { consumption } \\
(\%)\end{array}$} & \multicolumn{6}{|c|}{ Foaming temperature $\left({ }^{\circ} \mathrm{C}\right)$} \\
\hline & \multicolumn{2}{|c|}{155} & \multicolumn{2}{|c|}{165} & \multicolumn{2}{|c|}{170} \\
\hline & $\begin{array}{c}\text { Expansion } \\
\text { rate }(\%)\end{array}$ & $\begin{array}{l}\text { Half-life } \\
\text { time (s) }\end{array}$ & $\begin{array}{c}\text { Expansion } \\
\text { rate (\%) }\end{array}$ & $\begin{array}{l}\text { Half-life } \\
\text { time (s) }\end{array}$ & $\begin{array}{c}\text { Expansion } \\
\text { rate }(\%)\end{array}$ & $\begin{array}{l}\text { Half-life } \\
\text { time (s) }\end{array}$ \\
\hline 1.5 & 11.8 & 13.1 & 13.1 & 14.9 & 14.4 & 13.2 \\
\hline 2.5 & 15.1 & 12.3 & 15.2 & 12.0 & 15.7 & 12.4 \\
\hline 3.5 & 17.4 & 8.7 & 17.4 & 9.0 & 17.9 & 9.3 \\
\hline
\end{tabular}

Based on the above test result, it was found that when the water consumption for foaming was between $2.5 \%$ and $3.5 \%$ and the temperature was between $155^{\circ} \mathrm{C}$ and $170^{\circ} \mathrm{C}$, this kind of asphalt had great foaming properties. To maximize the comprehensive effects including expansion rate and the half-life time, the foaming temperature and water consumption of the selected asphalt were determined to be $165^{\circ} \mathrm{C}$ and $2.5 \%$, respectively. At the same time, the inflation rate and half-life time of selected foamed asphalt were $15.2 \%$ and 12.0 s, respectively.

\subsubsection{Aggregate}

This study adopted RCTB materials as aggregates. Due to cold in-place recycling mixture with foamed asphalt was used to be cement stabilized base, new aggregates was not added to RCTB materials to improve original gradation.

\subsection{Curing environment}

At present, there are two major methods as following for recycling mixture with foamed asphalt:

(1) Putting specimens into an air-circulating oven at $60^{\circ} \mathrm{C}$ and curing for $40 \mathrm{~h}$;

(2) Wrapping specimens in the plastic bags with sealing and Putting them into an air-circulating oven at $40^{\circ} \mathrm{C}$ and curing for $48 \mathrm{~h}$.

To study the influence of different curing conditions on mechanical performance of recycling mixture, two groups of standard Marshall specimens which had the same RCTB materials, dose of cement and foamed asphalt as well as the optimum moisture content, were obtained after 75 times compaction for double-sided. The first group was directly put into an oven at $60^{\circ} \mathrm{C}$, with curing for $1 \mathrm{~d}, 3 \mathrm{~d}, 5 \mathrm{~d}, 7 \mathrm{~d}$, respectively. The second group was wrapped in the plastic bag in an oven at $40^{\circ} \mathrm{C}$, and had the same curing ages as the first group.

\section{Analysis of Test Results}

As a key indicator for controlling the performance of recycling mixture in the base courses, moisture content under different curing conditions was analyzed, as shown in Table 3. Subsequently, various profiles of splitting strength and moisture content under different curing conditions were present, as shown from Fig 3 to Fig 4. 
Table 3 Results of splitting strength test and moisture content

\begin{tabular}{|c|c|c|c|l|c|}
\hline $\begin{array}{c}\text { Curing } \\
\text { conditions }\end{array}$ & $\begin{array}{c}\text { Curing } \\
\text { age (d) }\end{array}$ & $\begin{array}{c}\text { ITS } \\
\text { (MPa) }\end{array}$ & $\begin{array}{c}\text { Moisture } \\
\text { content (\%) }\end{array}$ & $\begin{array}{c}\text { Difference value of } \\
\text { ITS (MPa) }\end{array}$ & $\begin{array}{c}\text { Difference value of } \\
\text { Moisture content (\%) }\end{array}$ \\
\hline \multirow{4}{*}{ First method } & 1 & 0.46 & 0.93 & $/$ & $/$ \\
\cline { 2 - 6 } & 3 & 0.58 & 0.22 & 0.12 & 0.71 \\
\cline { 2 - 6 } & 5 & 0.60 & 0.19 & 0.02 & 0.03 \\
\cline { 2 - 6 } & 7 & 0.61 & 0.18 & 0.01 & 0.01 \\
\hline \multirow{3}{*}{$\begin{array}{c}\text { Second } \\
\text { method }\end{array}$} & 1 & 0.38 & 1.97 & $/$ & 0.32 \\
\cline { 2 - 6 } & 3 & 0.48 & 1.65 & 0.10 & 0.33 \\
\cline { 2 - 6 } & 7 & 0.56 & 1.32 & 0.08 & 0.40 \\
\hline
\end{tabular}

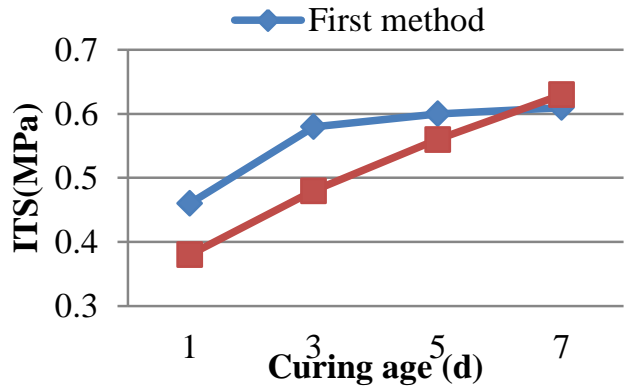

Fig. 3 ITS value under different different curing method

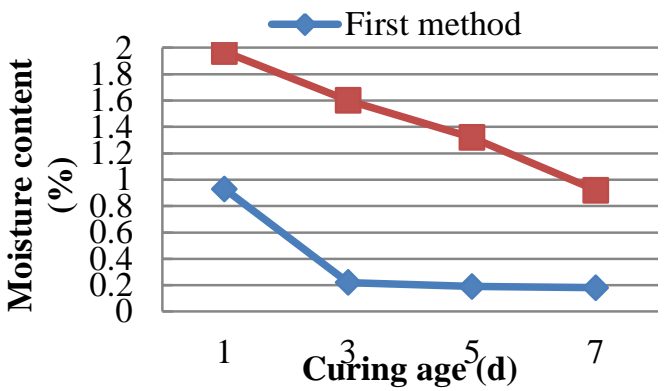

Fig. 4 Moisture content under curing method

Combined with Fig 3 and Fig 4, it can be revealed that under this curing condition, the rates of moisture loss and strength growth in cold recycling mixture were rapidly. So, the curing age of mixture did not have to be extended after the curing for 3d. For the second kind of curing condition, the moisture evaporation rate of recycling mixture was slow and the strength growth was relatively gentle, because of the sealed plastic bag. The strength of mixture had a certain degree of growth during the curing age for $7 \mathrm{~d}$. Similarly, it can be found that compared with the first condition, the early strength of mixture was lower under the second curing condition. However, with the prolongation of the curing age, the ultimate strength of moisture was greater. The causes of these above results contained two aspects. Firstly, under the first curing condition, the moisture in the specimen placed in the oven at $60^{\circ} \mathrm{C}$ was evaporated quickly, inhibiting the hydration of cement. Secondly, although the rates of moisture loss and strength growth of recycling mixture were slowly under the second mode of curing, the hydration reaction of cement could accomplish adequately, promoting the sufficient formation of the strength.

The difference of moisture content had good correlation with difference of ITS. It can be inferred that there was a close relation between the strength and the moisture content for the cold recycling mixture with foamed asphalt in the cement stabilized base. The difference of moisture content and ITS presented different rules shown in Fig 5, mainly because the rapid evaporation of moisture in the recycling mixture inhibited the hydration of cement and the strength of mixture mainly came from the adhesive action between the foamed asphalt and the aggregates under the first curing condition. Moreover, there was still more moisture used to cause hydration reaction of cement in the mixture, proving a definite strength for mixture under the second curing condition. 


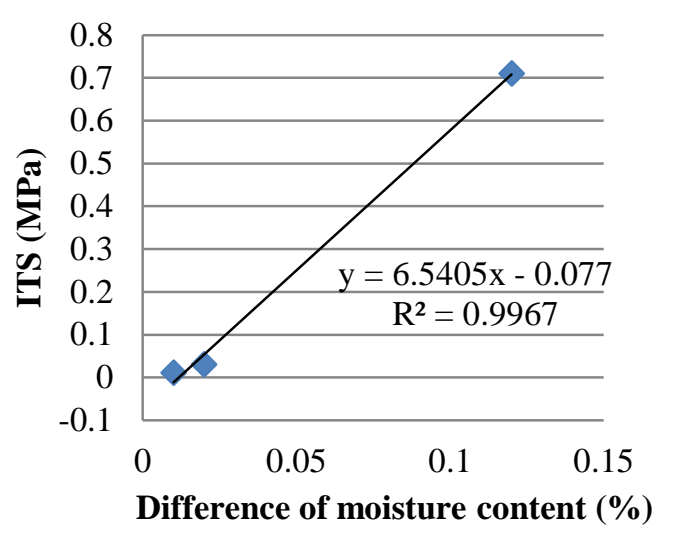

(a) First curing condition

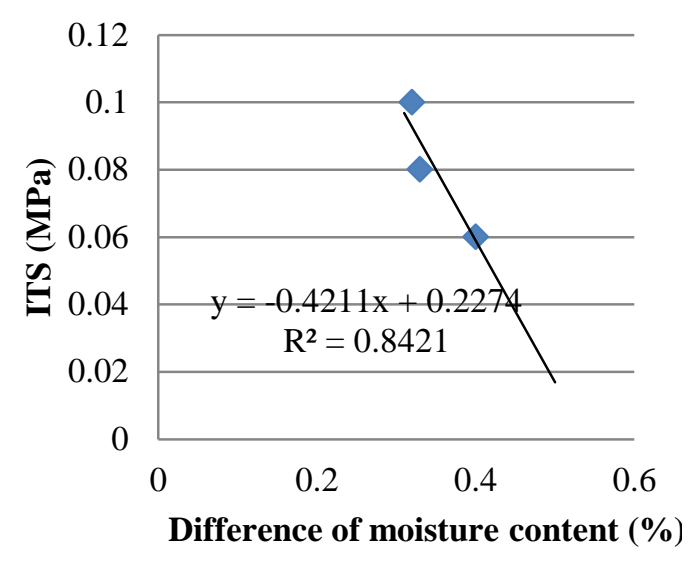

(b) Second curing condition

Fig. 5 Relationship under different curing conditions

\section{Conclusion}

During the paving process of cold recycling mixture with foamed asphalt as cement stabilized base in practical engineering, in order to ensure the recycling mixture has certain strength, the natural curing should be conducted for a certain time, so as to control the moisture content and strength of moisture. Otherwise, the moisture loss and strength growth of recycling mixture will be slowly due to the airtight environment of the overlying layers structure, leading to early damage. Compared with the unsealed curing condition at $60^{\circ} \mathrm{C}$, the cold recycling mixture with foamed asphalt in cement stabilized base had a greater strength and moisture content under the sealed curing condition at $40^{\circ} \mathrm{C}$. In addition, the changes of strength and moisture content with the increase of curing age are controllable and regular, which can provide theoretical basis for guiding the construction.

\section{References}

[1] S. Im. Impacts of laboratory curing condition on indirect tensile strength of cold in-place recycling mixtures using foamed asphalt[C]// Airfield and Highway Pavements. 2010:213-221.

[2] H. Wang. Effect of Curing temperature on pavement performance of cold recycling mixture and dispersity of foamed asphalt[J]. Highway. 2016(04):226-232.

[3] L. Chen, H. Z. Yi, H. B. Chen. Research of road performance of cold recycled pavement base with foamed asphalt based on fractal dimension[J]. Journal of Highway and Transportation Research and Development, 2016.2(1):1-5.

[4] A. Loizos, V. Papavasiliou, C. Plati. Early-life performance of cold-in-place pavement recycling with foamed asphalt technique[J]. Transportation Research Record Journal of the Transportation Research Board, 2007, 2005(1):36-43.

[5] A. González, F. Paniagua, G. Thenoux, et al. Effect of foamed bitumen content in laboratory tests[C]// ARRB Conference, 26th, 2014, Sydney, New South Wales, Australia. 2014.

[6] S. Sunarjono. Performance of foamed asphalt under repeated load axial test[J]. Procedia Engineering, 2013, 54:698-710.

[7] X. J. Li, F. Z. Shi, Y. P. Zhang. Influence of water percentage on performance of foamed bitumen mixture[J]. Journal of Building Materials, 2008, 11(1):64-69.

[8] K. J. Jenkins. Mix design considerations for cold and half-warm bituminous mixes with emphasis of foamed bitumen [D]. [Doctoral dissertation]. University of Stellenbosch, Stellenbosch, 2000 . 
[9] K. Kweir, D. Fordyce, G. Mccabe. Aspects influencing the performance of foamed bitumen stabilised aggregate mixtures[J]. Asphalt Yearbook, 2001.27-34.

[10] G.Y. Li, L. H. Li. Relationship between asphalt foaming effect and foamed asphalt mixture performance[J]. Journal of Building Materials, 2008, 11(5):555-560.

[11]H. I. Ozturk, M. E. Kutay. Sensitivity of nozzle-based foamed asphalt binder characteristics to foaming parameters[J]. Transportation Research Record Journal of the Transportation Research Board, 2014, 2444(1):120-129.

[12] S. Khosravifar, D. G. Goulias, C. W. Schwartz. Laboratory evaluation of foamed asphalt stabilized base materials[J]. Geotechnical Special Publication, 2014(225):1592-1601.

[13] P. J. Ruckel, S. M. Acott, R. H. Bowering. Foamed-asphalt paving mixtures: preparation of design mixes and treatment of test specimens[J]. Transportation Research Record, 1983(911):1-8.

[14] P. Fu, F. A. Halles, D. Jones, et al. Investigation of the curing mechanism of foamed asphalt mixes based on micromechanics principles[J]. Journal of Materials in Civil Engineering, 2010, 22(1):29-38.

[15] Y. B. Wu, J. J. Shi, C. F. Yang, et al. Experimental study on foamed asphalt warm mix technology[J]. Advanced Materials Research, 2014(919-921):1110-1114. 